\title{
Tumor-induced DNA methylation in the white blood cells of patients with colorectal cancer
}

\author{
PAPATSON BOONSONGSERM ${ }^{1,2}$, PHONTHEP ANGSUWATCHARAKON $^{2}$, \\ CHAROENCHAI PUTTIPANYALEARS ${ }^{2,3}$, CHATCHAWIT APORNTEWAN $^{4}$, NARISORN KONGRUTTANACHOK $^{5}$, \\ VITAVAT AKSORNKITTI $^{2}$, NAKARIN KITKUMTHORN ${ }^{6}$ and APIWAT MUTIRANGURA ${ }^{2,3}$ \\ ${ }^{1}$ Program of Medical Science, Faculty of Medicine; ${ }^{2}$ Department of Anatomy, Faculty of Medicine; \\ ${ }^{3}$ Center for Excellence in Molecular Genetics of Cancer and Human Disease, Faculty of Medicine; ${ }^{4}$ Department of \\ Mathematics, Faculty of Science; ${ }^{5}$ Department of Laboratory Medicine, Faculty of Medicine, Chulalongkorn University, \\ Bangkok 10330; ${ }^{6}$ Department of Oral Biology, Faculty of Dentistry, Mahidol University, Bangkok 10400, Thailand
}

Received January 17, 2019; Accepted July 11, 2019

DOI: $10.3892 / \mathrm{ol} .2019 .10638$

\begin{abstract}
The secretions of cancer cells alter epigenetic regulation in cancer stromal cells. The present study investigated the methylation changes in white blood cells (WBCs) caused by the secretions of colorectal cancer (CRC) cells. Changes in the DNA methylation of peripheral blood mononuclear cells (PBMCs) from normal individuals co-cultured with CRC cells were estimated using a methylation microarray. These changes were then compared against the DNA methylation changes and mRNA levels observed in the WBCs of patients with CRC. Procollagen-lysine, 2-oxoglutarate 5-dioxygenase 1 (PLODI) and matrix metalloproteinase $9(M M P 9)$ were selected to assess the DNA methylation of the WBCs from CRC patients using real-time methylation-specific PCR. The majority of the genes analyzed presented high levels of mRNA in the WBCs of the patients with CRC and DNA methylation in the co-cultured PBMCs. Intragenic methylation revealed the strongest association $\left(\mathrm{P}=8.52 \times 10^{-21}\right)$. For validation, $M M P 9$ and $P L O D 1$ were selected and used to test WBCs from 32 patients with CRC
\end{abstract}

Correspondence to: Professor Apiwat Mutirangura, Department of Anatomy, Faculty of Medicine, Chulalongkorn University, Pattayapat Building, Rama IV Road, Bangkok 10330, Thailand E-mail: mapiwat@chula.ac.th

Professor Nakarin Kitkumthorn, Department of Oral Biology, Faculty of Dentistry, Mahidol University, 5 Yothee Road, Bangkok 10400, Thailand

E-mail: nakarinkit@gmail.com

Abbreviations: CRC, colorectal cancer; WBCs, white blood cells; PBMCs, peripheral blood mononuclear cells; MSP, methylation-specific PCR; LINE-1, long interspersed nucleotide element-1; CU-DREAM, connection up- and downregulation expression analysis of microarrays; FFPE, formalin-fixed paraffin-embedded; H\&E, hematoxylin and eosin; PPV, positive predictive value; NPV, negative predictive value

Key words: CRC, WBCs, matrix metalloproteinase 9 methylation and 57 normal controls. The intragenic MMP9 methylation was commonly found $(\mathrm{P}<0.0001)$ with high sensitivity $(90.63 \%)$ and high specificity $(96.49 \%)$, and a positive predictive value of $93.33 \%$ and a negative predictive value of $93.22 \%$. PLOD1 methylation was revealed to have lower sensitivity $(30.00 \%)$ but higher specificity (97.92\%). In addition to circulating WBCs, MMP9 protein expression was observed in infiltrating WBCs and the metastatic lymph nodes of patients with CRC. In conclusion, $\mathrm{CRC}$ cells secrete factors that induce genome wide DNA methylation changes in the WBCs of patients with CRC. These changes, including intragenic MMP9 methylation in WBCs, are promising CRC biomarkers to be tested in future CRC screening studies.

\section{Introduction}

Several epigenetic biomarkers in peripheral blood and circulating cell-free DNA in serum and plasma have been reported for cancer diagnosis. The DNA methylation biomarkers of various cancers include: Adenomatous polyposis coli protein (APC), glutathione S-transferase Pi 1 (GSTP1), Ras association domain family member $1 A$ (RASSF1A), and retinoic acid receptor (RAR)- $\beta 2$ for breast cancer; BRCA1, HIC ZBTB transcriptional repressor 1 , paired box 5, progesterone receptor, and thrombospondin 1 for ovarian cancer; Cyclin D2, plasminogen activator urokinase, suppressor of cytokine signaling 1, thrombospondin, and von Hippel-Lindau tumor suppressor for pancreatic cancer; GSTP1, RASSF1, and $R A R B 2$ for prostate cancer; $P 15, P 16$, and $R A S S F 1 A$ for hepatocellular carcinoma; and $A P C, O-6$-methylguanine-DNA methyltransferase, RASSF $2 A$, WNT inhibitory factor-1, and Septin 9 (SEPT9) for colorectal cancer (CRC). All of the reported biomarkers exhibit different sensitivities and specificities for cancer detection (1). Furthermore, in colon, liver, lung, and nasopharynx cancers, significant DNA hypomethylation of long interspersed nucleotide element-1 (LINE-1) has been reported (2). Each candidate gene has been investigated using appropriate methods; PCR and pyrosequencing are suitable for quantitatively measuring DNA methylation levels. Typically, hypermethylation and hypomethylation are 
measured at specific loci from the promoter regions. However, the molecular mechanism underlying DNA methylation changes in circulating cells, cancer cells or white blood cells (WBCs), has not been determined.

In a previous study, we reported LINE-1 hypermethylation in micrometastatic lymph nodes and the surrounding cells in patients with breast cancer. Secretions from breast cancer cells were shown to increase LINE-1 methylation in cancer stromal cells (3). Therefore, we hypothesize that cancer secretions can alter the DNA methylation of circulating WBCs.

In CRC, cancer cells grow uncontrollably in the colon or rectal area (4). The majority of CRC develops from the inner lining of organs called polyps, with $\sim 5 \%$ of polyps becoming cancerous $(5,6)$. CRC is the third most common cancer and the fourth leading cause of death worldwide (7). The majority of cases of CRC occur in patients $>50$ years of age (8). In addition, several factors can increase the risk of CRC, including diet, obesity, lack of physical activity, alcohol consumption, tobacco use, family history of CRC, and hereditary conditions (9). Currently, the gold standard tool for CRC screening is colonoscopy, which has high sensitivity for the detection of CRC (10).

In the present study, whether CRC secretions cause methylation changes in the circulating WBCs of patients with $\mathrm{CRC}$ was examined. Connection up- and downregulation expression analysis of microarrays (CU-DREAM) (11) was used to compare the methylation profile of normal control peripheral blood mononuclear cells (PBMCs) after co-culturing with CRC cell lines and the RNA expression profiles of WBCs from patients with CRC. Methylation changes in the candidate genes in the WBCs of patients with CRC were evaluated using real-time methylation-specific PCR (RT-MSP).

\section{Materials and methods}

Ethical statement. The present study was approved by the Ethical Committee of the Faculty of Medicine, Chulalongkorn University (IRB no. 326/60). All samples were obtained from patients diagnosed with CRC between January 2016 and January 2018 in Chulalongkorn Memorial Hospital. All study subjects provided written informed consent.

Blood samples and formalin-fixed paraffin-embedded (FFPE) tissue. The blood samples for the co-culture model were obtained from 3 healthy males and 2 healthy females with no immune disorders or chronic diseases. The blood samples for the methylation tests were obtained from $32 \mathrm{CRC}$ patients and 57 normal controls. Various FFPE tissues were examined in the present study by immunohistochemical staining using anti-matrix metalloproteinase (MMP)-9 antibodies; the tissue samples were comprised of normal colon biopsies (5 cases), tumor colon biopsies (5 cases) and a complete metastatic lymph node (1 case). Normal controls and CRC patients were investigated directly by colonoscopy. The biopsies were stained with hematoxylin and eosin (H\&E) for histopathological confirmation of the components by a pathologist.

PBMC isolation. Firstly, whole blood was diluted with an equal amount of $1 \mathrm{X}$ phosphate-buffered saline (PBS). The diluted blood solution was placed on top of Ficoll-Paque gradient media (GE Healthcare Bio-Sciences) in tubes for centrifugation at room temperature for $20 \mathrm{~min}$ at $1,020 \mathrm{x} \mathrm{g}$. Next, the PBMCs were carefully collected from the interface layer between the blood plasma and Ficoll solution. The collected PBMCs were washed with 1X PBS and then centrifuged at $640 \times \mathrm{g}$ twice, and were then resuspended in freezing media [10\% DMSO in fetal bovine serum (FBS; Thermo Fisher Scientific, Inc.)] at a concentration of $1 \times 10^{7} \mathrm{PBMCs} / \mathrm{ml}$ (12).

Cell lines and co-culture conditions. The following human $\mathrm{CRC}$ cell lines were obtained from the American Type Culture Collection (ATCC): SW480 (ATCC ${ }^{\circledR}$ CCL-228 ${ }^{\mathrm{TM}}$ ), representing early-stage CRC in a 50-year-old male and HT29 (ATCC $^{\circledR}$ HTB-38 ${ }^{\mathrm{TM}}$ ), representing early-stage CRC in a 44-year-old female. All cell lines were grown in Dulbecco's modified Eagle's medium (DMEM; Gibco; Thermo Fisher Scientific, Inc.) supplemented with $10 \% \mathrm{FBS}, 0.1 \mathrm{mg} / \mathrm{ml}$ streptomycin, and $100 \mathrm{U} / \mathrm{ml}$ penicillin at $37^{\circ} \mathrm{C}$ in a humidified atmosphere (95\% air: $5 \% \mathrm{CO}_{2}$ ). The cell lines were grown in $25 \mathrm{CC}$ culture flasks (Corning Inc.) and were harvested at $80 \%$ confluence with $0.05 \%$ trypsin. The cell lines were washed with $1 \mathrm{X}$ PBS.

The co-culture technique was used to study the effects of substances released from CRC cells and PBMCs. Cancer cells and PBMCs were co-cultured in Transwell ${ }^{\circledR}$ culture plates (Costar; Corning Inc.). CRC cells were seeded in 24-well culture plates $\left(5 \times 10^{4}\right.$ cells/well), which were then filled with medium (DMEM with $10 \%$ FBS) and incubated in a $\mathrm{CO}_{2}$ incubator at $37^{\circ} \mathrm{C}$ in a humidified atmosphere for $24 \mathrm{~h}$. PBMCs were co-cultured with $\mathrm{CRC}$ cells in permanent membrane cultures $\left(1 \times 10^{5}\right.$ cells/well), which were incubated for $4 \mathrm{~h}$ in a $\mathrm{CO}_{2}$ incubator at $37^{\circ} \mathrm{C}$ in a humidified atmosphere before harvesting for DNA extraction.

DNA extraction. In the present study, genomic DNA was extracted from two sample types: Co-cultured PBMCs and blood samples. The co-cultured PBMCs were centrifuged at $700 \mathrm{x} \mathrm{g}$ for $15 \mathrm{~min}$ and the supernatant was discarded. The PBMC pellets were then washed with $1 \mathrm{X}$ PBS and centrifuged $700 \mathrm{x} g$ for $15 \mathrm{~min}$. The blood samples were added to an equal amount of red blood cell lysis buffer to lyse the red blood cells, then centrifuged at $700 \mathrm{x}$ g for $15 \mathrm{~min}$; the resulting supernatant was discarded. The WBC pellets were washed with 1X PBS and centrifuged at $700 \times \mathrm{g}$ for $15 \mathrm{~min}$ twice. All cell pellets were supplemented with $500 \mu \mathrm{l}$ of extraction buffer containing $10 \%$ SDS and proteinase $\mathrm{K} 0.5 \mathrm{mg} / \mathrm{ml}$. Then, the cell solutions were mixed together and incubated for $72 \mathrm{~h}$ in a water bath at $50^{\circ} \mathrm{C}$. The DNA was extracted using a phenol: Chloroform: Isoamyl alcohol (25:24:1) solution and the mixtures were centrifuged at $4^{\circ} \mathrm{C}$ and $14,000 \mathrm{x}$ g for $15 \mathrm{~min}$. The upper aqueous phase was carefully collected and transferred to a fresh tube, and then absolute ethanol was added for DNA precipitation before centrifugation at $4^{\circ} \mathrm{C}$ and $14,000 \mathrm{x}$ g for $15 \mathrm{~min}$. The supernatant was discarded and the DNA was washed with $70 \%$ ethanol at $4^{\circ} \mathrm{C}$ then centrifuged at $14,000 \times \mathrm{g}$ for $15 \mathrm{~min}$ twice. The obtained DNA was air-dried and then dissolved in distilled water. DNA samples were converted by sodium bisulfite treatment using the EZ DNA Methylation-Gold ${ }^{\mathrm{TM}}$ kit (Zymo Research Corp.) according to the manufacturer's instructions.

Methylation microarray. The genome-wide DNA methylation profiling of the co-cultured PBMCs was carried out using 
the recently developed Illumina Infinium MethylationEPIC BeadChip (Illumina, Inc.), which accesses the DNA methylation profile across $\sim 850,000 \mathrm{CpGs}$. Samples in the present study included duplicate female control PBMCs and duplicate male control PBMCs. The duplicate female PBMCs were co-cultured with HT29 cells and the duplicate male PBMCs were co-cultured with SW480 cells. The methylation profiling obtained in the present study is available in the Gene Expression Omnibus (GEO) database under the reference, GSE110274.

Retrieval of data from GenBank. Gene expression profiles obtained by microarray were obtained from GEO datasets (www.ncbi.nlm.nih.gov/gds) using keywords including 'colorectal cancer' and 'blood'. GSE11545 (Applied Biosystems; Thermo Fisher Scientific, Inc.) (13) and GSE10715 (Affymetrix; Thermo Fisher Scientific, Inc.) (14) were used to represent the expression profiling of peripheral blood samples. GSE110274 (Illumina, Inc.) is the methylation profile obtained from the present experiment with co-cultured PBMCs.

$C U$-DREAM. In the present study, gene expression probes were always in genes and were tagged with their host genes. Unlike the expression probes, some methylation probes were in genes, while some methylation probes were not. The methylation probes were classified by their location. Intragenic probes were in genes and upstream probes were located 5,000 bp upstream of genes. All intragenic and upstream probes were tagged with their host genes. A comparison between experimental and control groups resulted in upregulated (up) or downregulated (dn) or 'neural' at every probes. A gene was said to be 'up' if there was at least a single probe in which the level of the experimental group was significantly higher (Student's t-test). The association between gene expression and methylation was identified by means of $2 \times 2$ contingency tables. A table consisted of 4 numbers denoted by a, b, c and $d$. The first and the second rows were up- or down-methylated genes and the rest, respectively. The first and the second columns were up- or down-expressed genes and the rest, respectively. Each $2 \times 2$ contingency table produced odds ratios (ORs) and Chi-square P-values (11).

RT-MSP of MMP9 and procollagen-lysine,2-oxoglutarate 5-dioxygenase 1 (PLOD1). The present study examined the methylation status of genes including MMP9 and PLOD1 in the WBCs from patients with CRC and normal controls using RT-MSP. The PCR Master Mix was prepared using PowerU ${ }^{\mathrm{TM}}$ $\mathrm{SYBR}^{\circledR}$ Green Master Mix (Thermo Fisher Scientific, Inc.) with primer sets specific for methylated bisulfite-modified DNA for the quantification of methylation levels and unmethylated bisulfite-modified DNA as an internal control. The PCR reactions of $M M P 9$ and $P L O D 1$ were quantified using Applied Biosystems QuantStudio 6 Flex Real-Time PCR System (Thermo Fisher Scientific, Inc.). For each gene, the primers were designed from the $\mathrm{CpG}$ position in the intragenic region. The primer sequences for $M M P 9$ amplification were: Forward methylated primer, 5'-TTGTTATTTTTTTTTTATTTTCGA GGGTC-3' and reverse methylated primer, 5'-GTAATACTA CACCAAAACAAACCG-3'; forward unmethylated primer, 5'-GTTTGTTATTTTTTTTTTATTTTTGAGGGTT-3' and reverse unmethylated primer, 5'-TTTTTCATAATACTACAC
CAAAACAAACCA-3'. The thermocycling conditions for $M M P 9$ were as follows: 45 cycles of $95^{\circ} \mathrm{C}$ for $45 \mathrm{sec}$ and $54^{\circ} \mathrm{C}$ for $45 \mathrm{sec}$. The primer sequences for PLODI amplification were: Forward methylated primer, 5'-TAAAAGGTTATTTGA TTTTTGATGTC-3' and reverse methylated primer, 5'-TCA AAAAAACAAAAAAACCTACG-3'; forward unmethylated primer, 5'-TTGTAAAAGGTTATTTGATTTTTGATGTT-3' and reverse unmethylated primer, 5'-TTTTTCTCAAAAAAA CAAAAAAACCTACA-3'. The thermocycling conditions for PLOD1 were as follows: 45 cycles of $95^{\circ} \mathrm{C}$ for $45 \mathrm{sec}$ and $54^{\circ} \mathrm{C}$ for $45 \mathrm{sec}$.

The DNA methylation levels for each sample were measured and compared to standard curves for methylated MMP9 and PLOD1. Firstly, the standard curves were created using completely methylated bisulfite converted DNAs (Qiagen, Inc.) diluted to give DNA concentrations of 10, 1, 0.1 and $0.01 \mathrm{ng} / \mu 1$, respectively. The diluted DNA samples were then subjected to RT-MSP, and the MMP9 and PLODI methylation levels were calculated from the obtained $\mathrm{Cq}$ values. The formulae for the standard curves for methylated MMP9 and PLOD1 were $\mathrm{y}=3 \times 10^{28} \times \mathrm{X}^{-20.22}$ (Fig. S1) and $\mathrm{y}=4 \mathrm{x} 10^{24} \mathrm{xX}^{-17.09}$ (Fig. S2), respectively. Thus, the Cq values for each sample can be measured for the absolute quantification of DNA methylation levels (15).

Immunohistochemistry. FFPE tissue samples were embedded in paraffin according to the protocol used in the Surgical Pathology Department. Sections $(3 \mu \mathrm{m})$ were fixed in formalin solution and dehydrated in alcohol solution. The sections were then incubated with rabbit polyclonal anti-MMP9 (dilution 1:500; cat. no. HPA001238; Sigma-Aldrich; Merck $\mathrm{KGaA}$ ) for $1 \mathrm{~h}$ for detection. Immunohistochemical staining was performed using an ultraView Universal 3,3'-diaminobenzidine tetrahydrochloride (DAB) Detection kit (Roche Diagnostics) containing horseradish peroxide and DAB, followed by counterstaining with hematoxylin on a BenchMark XT (Roche Diagnostics) automated system. The positive WBCs can be visualized by a brown colored precipitate.

Statistical analysis. All statistical analyses were performed using SPSS for Windows, version 17.0 (SPSS Inc.). The mean and the standard error of the mean (SEM) were calculated and Student's t-tests were performed to determine significant differences in methylation changes in the WBCs from patients with CRC and normal controls. The P-values obtained were two-sided and $\mathrm{P}<0.05$ was considered to indicate a statistically significant difference. Receiver operating characteristic (ROC) curve analysis was carried out to differentiate the capacities of MMP9 and PLODI for methylation changes between patients with $\mathrm{CRC}$ and normal controls.

\section{Results}

Bioinformatics analysis of DNA methylation and mRNA array profiling. The flowchart in Fig. 1 illustrates the process followed in the present study. The methylation profile of Group 1 (GSE110274) from co-cultured PBMCs and the RNA expression profiles of Groups 2 and 3 (GSE11545 and GSE10715) from peripheral blood samples were interpreted to identify the 
genes in common using CU-DREAM analysis. The candidate genes were hypermethylated and upregulated genes from group (a) with a $\mathrm{P}<0.01$ and an OR of $>1$. The results of the analysis are presented in Tables I and SI, along with the P-values, ORs, and 95\% confidence intervals (95\% CIs). Genes from the PBMCs that were methylated at intragenic locations as a result of co-culturing with CRC cell lines were found to be upregulated in the WBCs of CRC patients $\left(\mathrm{P}<3 \times 10^{-14}\right)$. An association between the DNA methylation of upstream locations and upregulation was also observed $\left(\mathrm{P}<4 \times 10^{-3}\right)$.

The candidate genes were selected from overlapping genes from the 3 data groups and were classified by biological process based on gene ontology, as shown in Table II. The validation genes were selected based on gene function, biological process, and the reported literature. PLODI was selected as a validation gene from genes overlapping the 3 data groups: GSE110274, GSE11545, and GSE10715. MMP9 was selected as a validation gene from the two data groups: GSE110274 and GSE10715.

MMP9 and PLOD1 methylation test by RT-MSP. MMP9 and $P L O D 1$ were selected to validate the DNA methylation of the WBCs from 32 CRC patients (Table SII) and 57 normal controls by RT-MSP. The present study measured the $\mathrm{Cq}$ values of each sample and then calculated the absolute methylation levels from the standard curves derived from the $\mathrm{Cq}$ values of the diluted methylated DNA. The concentration of methylated $M M P 9$ of the samples ranged from 0.0004 to $3.5088 \mathrm{ng} / \mu \mathrm{l}$. The mean and SEM of the methylated MMP9 levels from the CRC patients and normal controls were $0.7226 \pm 0.1369$ and $0.0487 \pm 0.0061 \mathrm{ng} / \mu \mathrm{l}$, respectively $(\mathrm{P}<0.0001)$, as shown in Fig. 2A. The comparison of methylated MMP9 levels in CRC patients and normal controls revealed high sensitivity, specificity, positive predictive value (PPV), and negative predictive value (NPV) of 90.63, 96.49, 93.33 and $93.22 \%$, respectively, with a cut-off at 0.1445 and area under the ROC curve of 0.9846, as shown in Fig. 2C. Furthermore, the concentration of methylated PLODI of the samples ranged from 0.0044 to $3.4091 \mathrm{ng} / \mu 1$. The mean and SEM levels of methylated PLODI from the CRC patients and normal controls were $0.4204 \pm 0.1259$ and $0.0967 \pm 0.0131 \mathrm{ng} / \mu \mathrm{l}$, respectively $(\mathrm{P}=0.0019)$, as shown in Fig. 2B. The examination of methylated $P L O D 1$ revealed low sensitivity and high specificity values of 30.00 and $97.92 \%$, respectively, with a cut-off at 0.3301 and area under the ROC curve of 0.7167, as shown in Fig. 2D.

Immunohistochemical staining differentiates colorectal tissue. The present study validated the expression of MMP9 in WBCs via the immunohistochemical staining of CRC samples. The samples were stained with H\&E and immunostained using anti-MMP-9 antibody. The normal epithelial area of CRC patients showed a low number of MMP9-positive WBCs (Fig. 3A). A large number of MMP9-positive WBCs were observed to infiltrate the WBCs of CRC patients (Fig. 3B). The metastatic lymph node from a late-stage CRC patient also showed a large number of MMP9-positive WBCs in the lymph node containing CRC metastases (Fig. 3C).

\section{Discussion}

DNA methylation in circulating cells can be derived from two cell types: Circulating tumor cells and WBCs (16). The
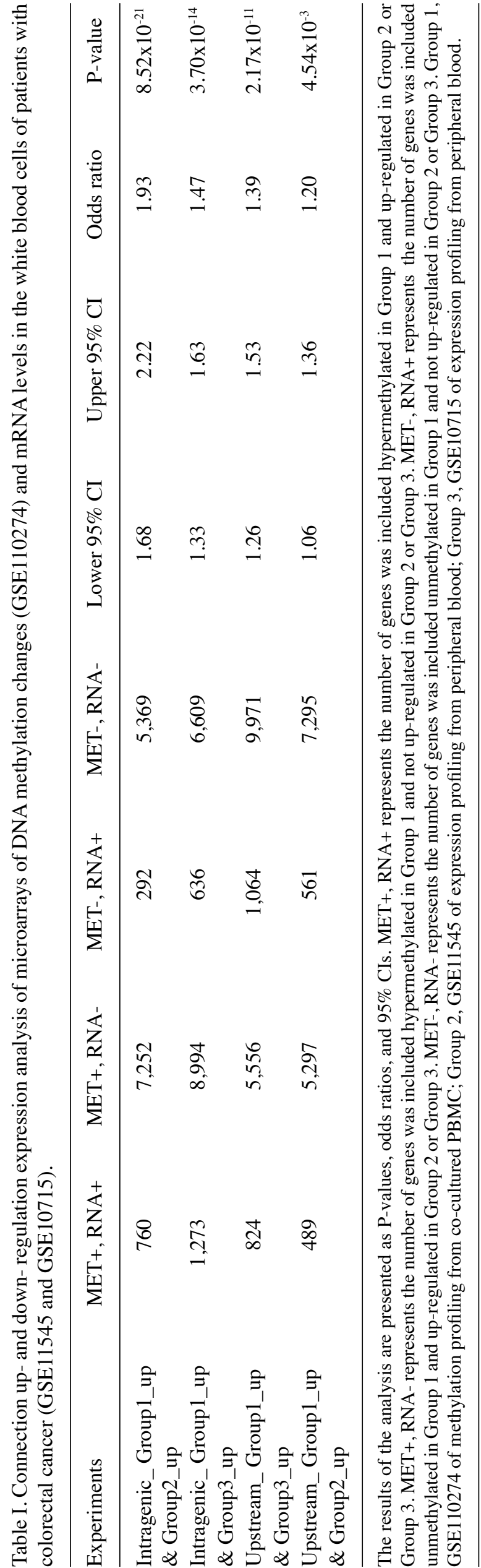


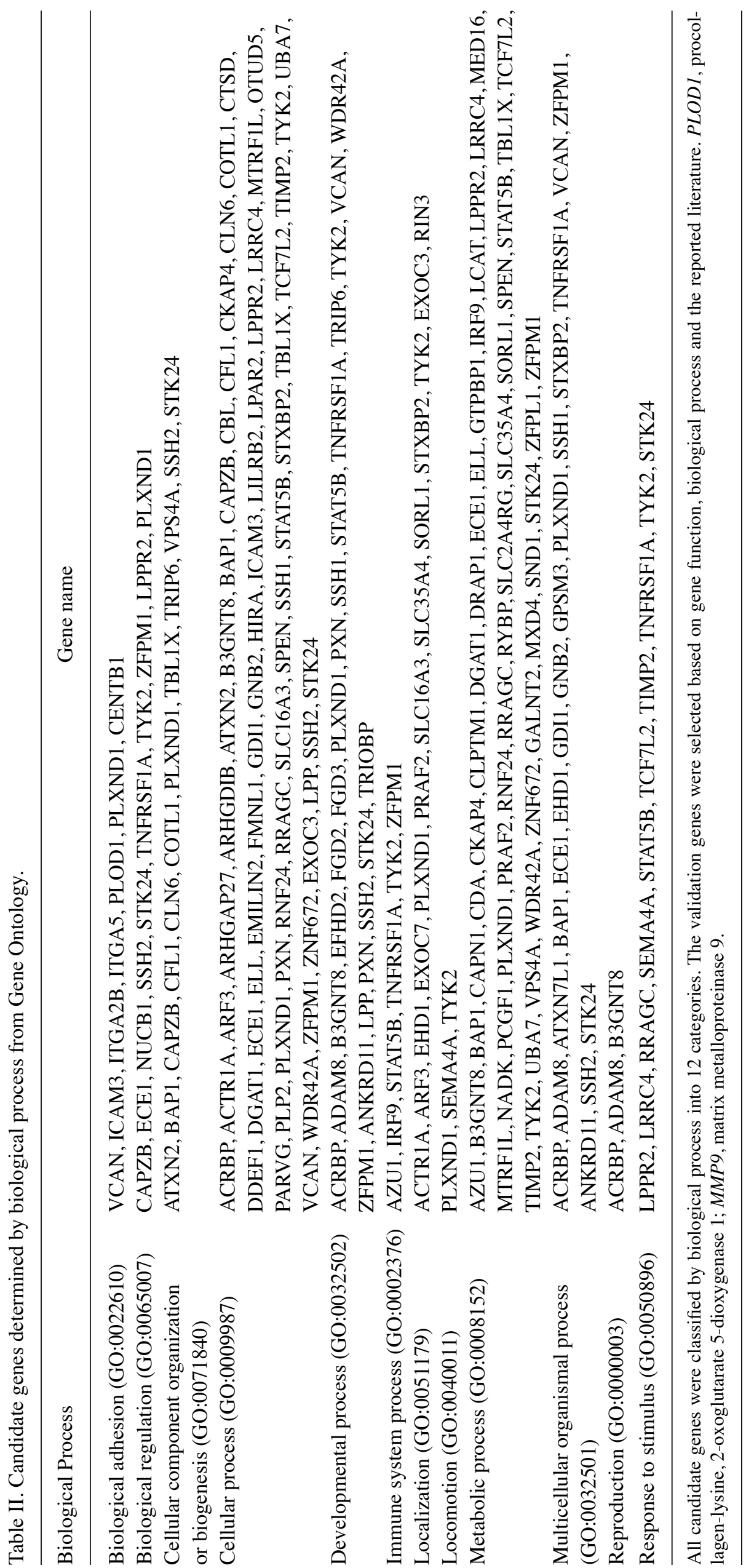




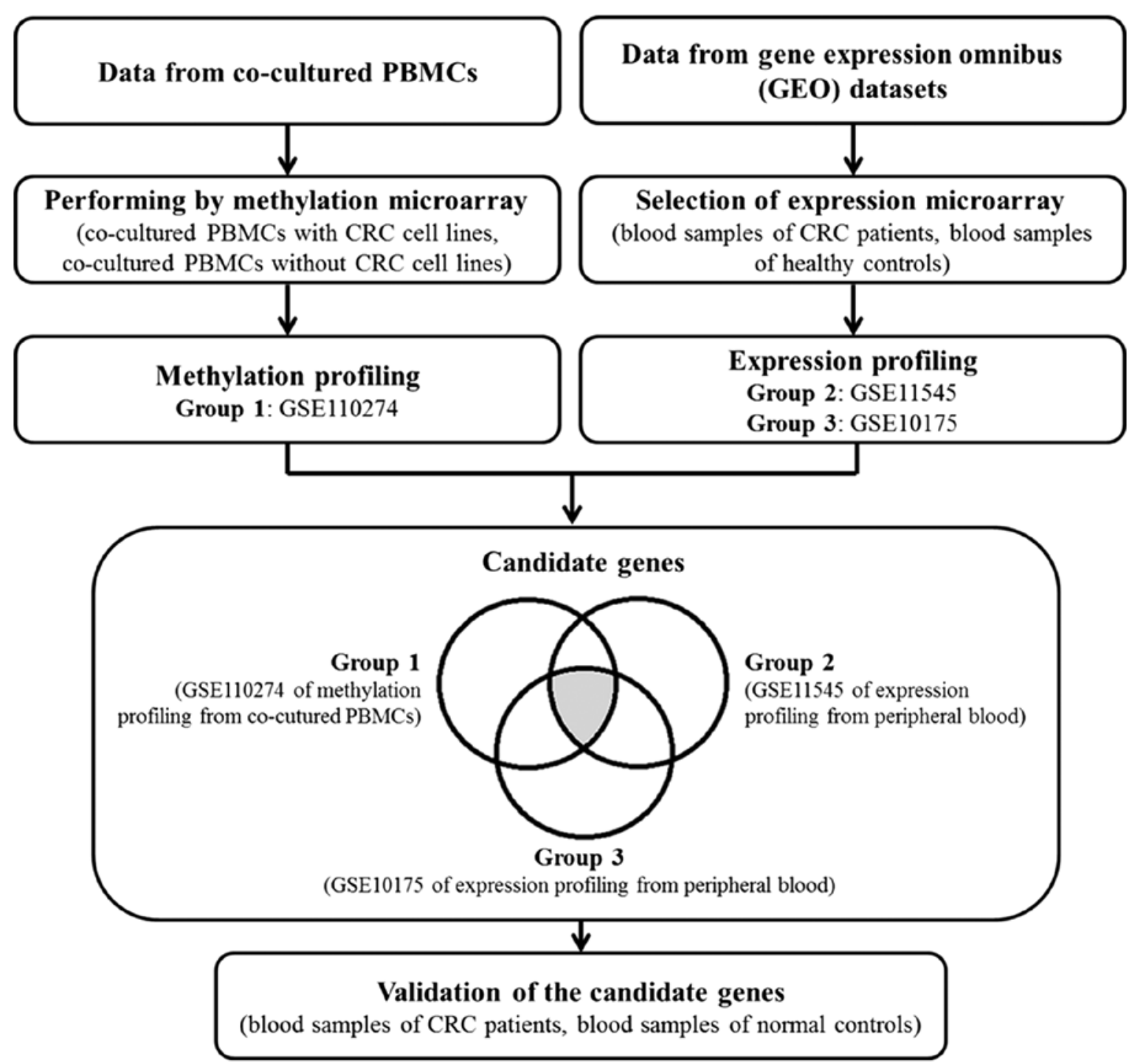

Figure 1. A flow chart of the methods employed in the present study. Data were processed and the candidate genes were collected. Group 1 represents DNA methylation changes (GSE110274), and Groups 2 and 3 represent the mRNA levels of the WBCs of patients with CRC (GSE11545 and GSE10715, respectively). All groups were analyzed by connection up- and downregulation expression analysis of microarrays. The association between gene expression and methylation was identified by means of $2 \times 2$ contingency tables. Each $2 \times 2$ contingency table produced ORs and $\chi^{2}$ P-values. The candidate genes were collected from the overlapping genes of the 3 data groups, which were hypermethylated and upregulated genes with a $\mathrm{P}<0.01$ and an OR of $>1$. Then, the present study selected genes of interest from gene function, biological process and the reported research literatures. The validated genes were quantified methylation using reverse transcription-quantitative methylation-specific PCR in WBCs of patients with CRC compared with normal controls. OR, odds ratio; WBCs, white blood cells; CRC, colorectal cancer; PBMCs, peripheral blood mononuclear cells.

number of circulating tumor cells is generally low and is dependent on the tumor size and metastasis status. Therefore, circulating cancer cell-derived tumor markers, in general, have low sensitivity. Previously, we demonstrated that breast cancer cells secrete factors that promote the expression of Mucin 1 (MUC1) by plasma cells (B lymphocytes in peripheral tissues). We also detected a large number of MUC1-positive plasma cells in micrometastatic lymph nodes (3). Therefore, tumor-induced molecular changes in WBCs can be used as a highly sensitive tumor marker. As cell secretion is a biologically active process, a large number of WBCs receive secretory molecules from cancer cells, regardless of the tumor size. The present study proved that in addition to infiltrating cells, CRC secretions can alter circulating WBCs and these changes can be used as sensitive circulating tumor markers. However, further exploration is required to determine whether the induced WBCs were infiltrating WBCs that migrated into the circulation or if $\mathrm{CRC}$ secretions play an endocrine role, targeting circulating WBCs.

The nature of CRC secretions inducing DNA methylation in WBC genomes remains to be explored. Several cytokines, including fibroblast growth factor 2, granulocyte-macrophage colony stimulating factor, interleukin (IL)-1 $\beta, I L-6$, macrophage inflammatory protein-1 $\alpha$, platelet-derived growth factor-BB, tumor necrosis factor- $\alpha$, and vascular endothelial growth factor have been reported at higher levels in the blood of patients with CRC (17). These cytokines potentially play a role in the DNA methylation of WBCs. Nevertheless, there are other types of cancer cell secretory molecules, including microRNA, exosomes, cells, mRNA, DNA, and proteins (18-20). All of these molecules should be evaluated to determine if they can induce DNA methylation. 

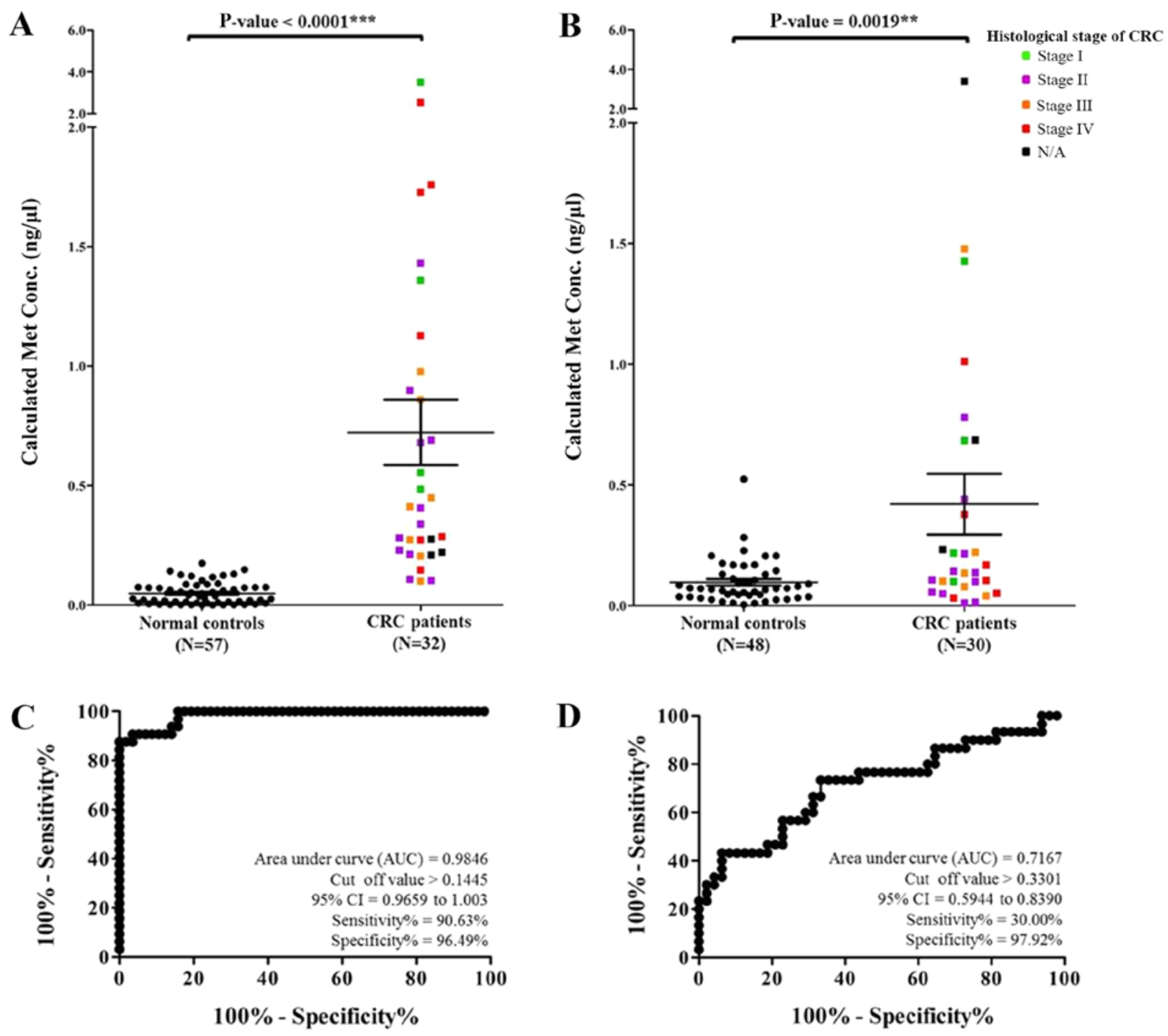

Figure 2. Methylation in white blood cells as determined by reverse transcription-quantitative methylation-specific PCR. (A) Scatter plot of $M M P 9$ methylation between 32 patients with CRC and 57 normal controls. The levels of $M M P 9$ methylation are expressed as the mean \pm standard error of the mean. ${ }^{* * *} \mathrm{P}<0.0001$. (B) Scatter plot of PLOD1 methylation between 30 CRC patients and 48 normal controls. The levels of PLOD1 methylation are expressed as the mean \pm standard error of the mean. ${ }^{* *} \mathrm{P}=0.0019$. (C) ROC curve of $M M P 9$ methylation exhibiting a satisfactory validated gene with high sensitivity ( $\left.90.63 \%\right)$ and high specificity (96.49\%). (D) ROC curve of PLOD1 methylation showing an unsatisfactory validated gene with low sensitivity (30.00\%) but high specificity (97.92\%). MMP9, matrix metalloproteinase 9; CRC, colorectal cancer; PLOD1, procollagen-lysine, 2-oxoglutarate 5-dioxygenase 1; ROC, receiver operator characteristic.

The most commonly known role of DNA methylation is the downregulation of gene expression via the methylation of promoters. CRC secretions were reported to methylate intragenic or upstream locations and increase mRNA levels. Gene body methylation sequences are frequently affected in highly expressed genes (21). The hypomethylated intragenic LINE-1 was reported to decrease the expression of cancer-associated genes in the formation of L1-RNA-AGO2 complexes $(22,23)$. Similarly, the hypermethylated intragenic LINE-1 upregulates genes from these complexes as well (3). Hypermethylation in the upstream region was reported to play a role in regulating alternative promoters $(24,25)$. We hypothesized that DNA methylation of upstream sequences might lead to the use of alternate but stronger promoters, resulting in upstream methylation increasing mRNA levels.

PLODI and MMP9 were selected to represent hypermethylated and upregulated genes for validation. The present study selected both genes from the results that had the highest OR and P-value. Both genes were hypermethylated at intragenic locations in PBMCs and upregulated in WBCs. Primers were designed for the methylation tests according to $M M P 9$ and PLODI oligonucleotide gene probes. The results of the methylation test presented hypermethylation. The present study then examined the protein expression of MMP9 in the WBCs of colon cancer tissues and lymph nodes of colon cancer patients. The immunohistochemistry results demonstrated positive staining of MMP9 in WBCs. Thus, these examinations produced similar results. The methylation of the $M M P 9$ gene is in the gene body and upregulation of gene body methylation has been reported previously $(21,22)$.

PLODI is related to collagen synthesis and assembly. This gene has been reported in the literature as being involved in CRC, especially in tumor progression $(26,27) . M M P 9$ is involved in the degradation of collagen from extracellular 
A

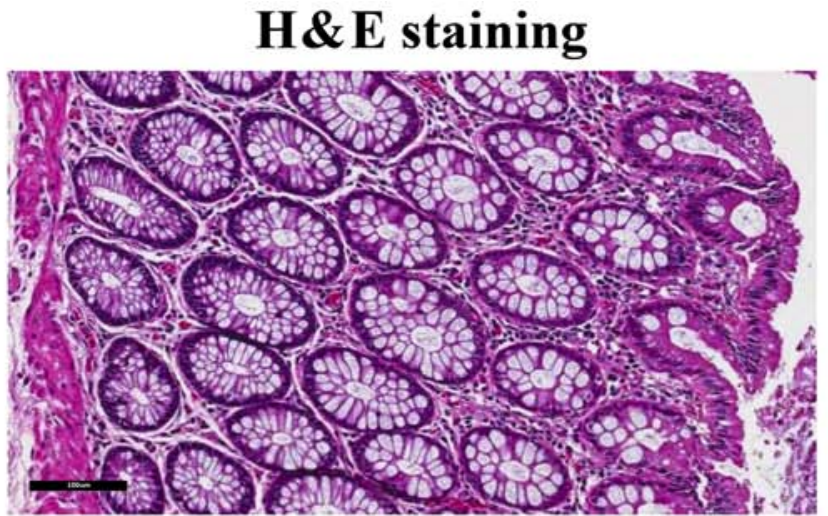

Immunohistochemistry staining

B
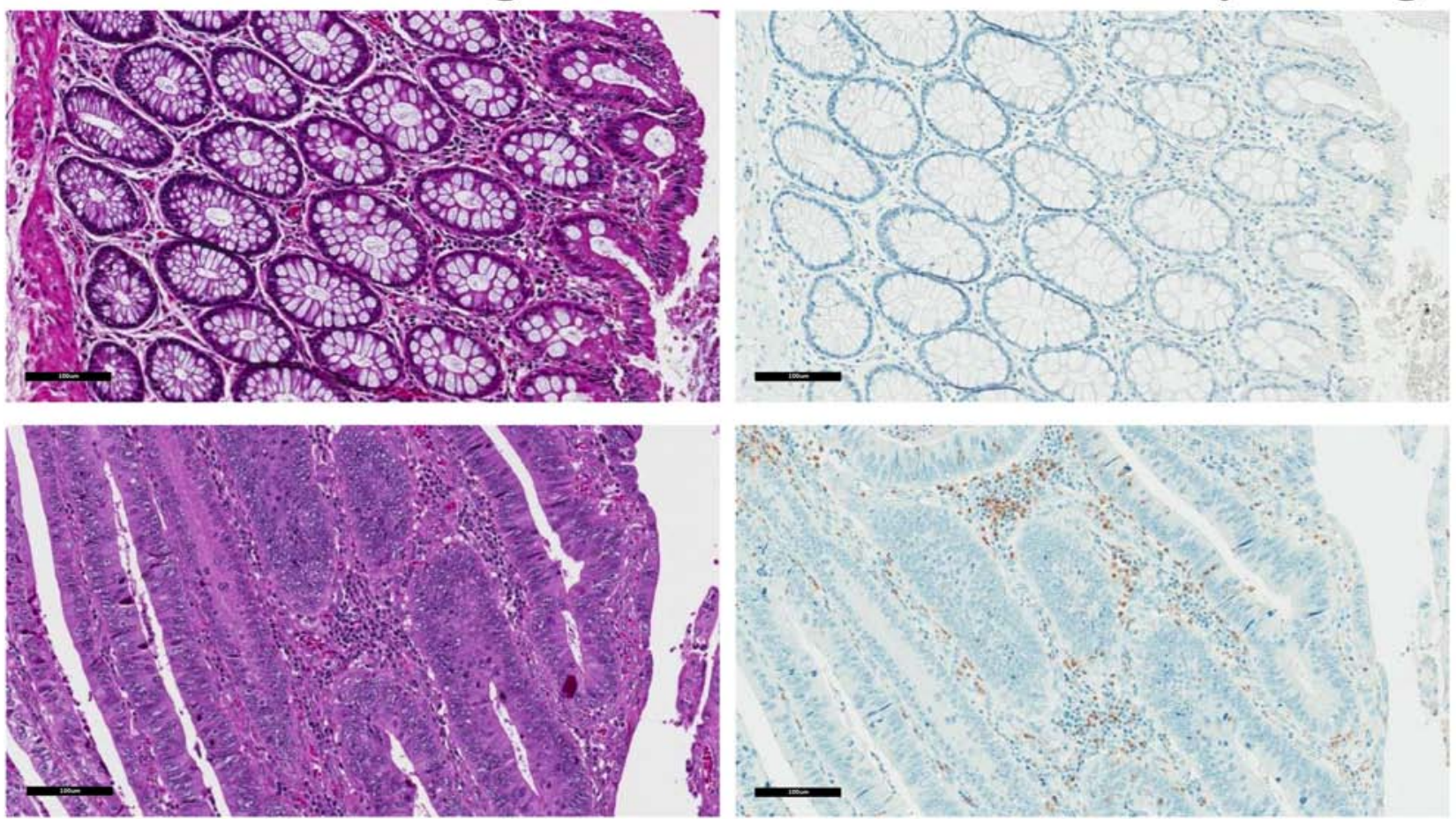

C
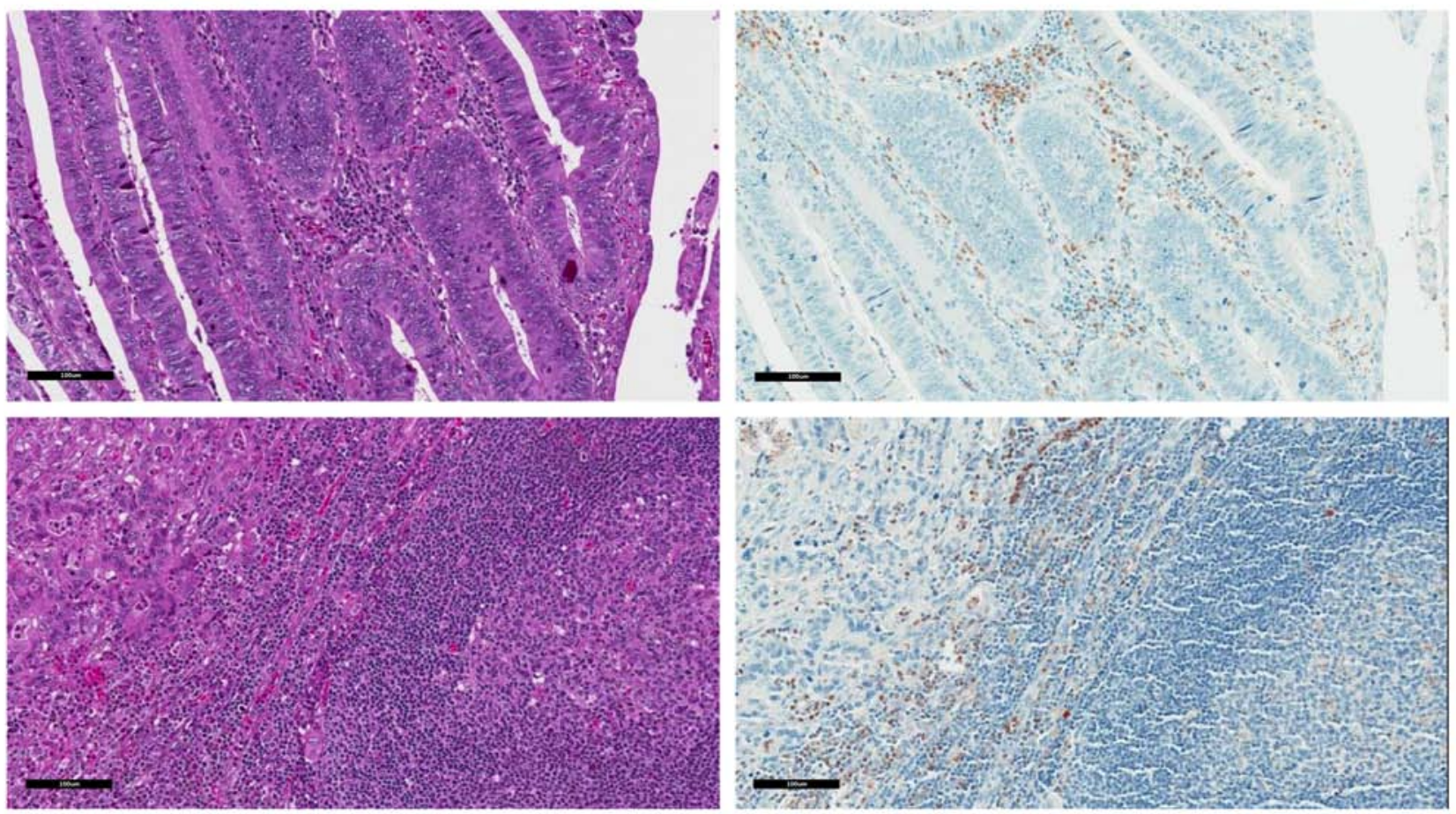

Figure 3. Formalin-fixed paraffin-embedded samples of patients with CRC were stained with $\mathrm{H}$ \& E, and immunohistochemistry staining with the anti-MMP9 antibody (magnification, x200). (A) Normal colon tissue of a patient with CRC exhibited few MMP9 positive WBCs (5-10\%). (B) A large number of CRC infiltrating MMP9 positive WBCs (60-70\%). (C) Metastatic lymph node of late-stage disease showed a large number of CRC infiltrating MMP9 positive WBCs (50-60\%). CRC, colorectal cancer; MMP9, matrix metalloproteinase 9; WBCs, white blood cells; H \& E, hematoxylin and eosin.

matrix components in normal physiological processes. Several studies have revealed a correlation between $M M P 9$ and $\mathrm{CRC}$, including in tumor angiogenesis, tumor invasion and inflammatory response (28-32). Epigenetic modifications are significantly involved with gene expression in cancer development (33). Thus, CRC progression may alter the epigenetic regulation of these genes.

To the best of our knowledge, this is the first report of MMP9 and PLOD1 methylation in the PBMCs of CRC. To apply these biomarkers for screening tests, the present study selected WBC isolation to examine methylation status, which is easier and faster than PBMC isolation. We tested the colon tissues of patients with colon cancer. The results of protein expression between WBCs and PBMCs revealed similar levels therefore we chose WBCs instead of PBMCs.

Intragenic methylation of $M M P 9$ is a good candidate for further clinical studies, including CRC screening, due to its high sensitivity (90.63\%), specificity (96.49\%), PPV (93.33\%), and NPV (93.22\%). Conversely, the validation results from the
PLOD1 methylation test were unsatisfactory, with low sensitivity $(30.00 \%)$ but high specificity $(97.92 \%)$. These methylation changes were not found to correlate with tumor grade or stage. Many biomarkers have been reported for CRC screening. For example, methylation tests have been reported for the hypermethylated DNA promoter regions of ALX homeobox 4, bone morphogenetic protein 3, neuronal pentraxin 2, RARb, Syndecan 2, SEPT9, and Vimentin, with an overall sensitivity of $90.70 \%$ and specificity of $72.50 \%$ in plasma samples (34). In particular, SEPT9 was reported to have a sensitivity of $48.20-90.00 \%$ and specificity of 88.00-91.50\% (35,36). In global DNA, hypomethylation of LINE-1 was reported to have a sensitivity of $52.78 \%$ and specificity of $86.81 \%$ in blood samples $(2,37)$. The majority of cases of hereditary CRC syndrome involve point mutations of tumor-suppressor genes, such as $A P C$ and $p 53$, with detection rates of 30.40 and $34.20 \%$, respectively, and oncogenes, such as $K$-ras, with a detection rate of $34.00 \%$ and a mutation frequency of $75.00 \%$ in tumor tissues found in serum $(38,39)$. In gene expression tests, $M M P 2$ and $M M P 9$ were significantly 
expressed in plasma samples (40). In the protein expression tests using ELISA in blood samples, TIMP metallopeptidase inhibitor-1 was reported to have a sensitivity of $63.00 \%$ and specificity of $98.00 \%$ (41).

In conclusion, CRC cells release secretions that induce DNA methylation changes in circulating WBCs. Both upstream and intragenic methylation of the genes were revealed to be associated with higher levels of the mRNAs. Finally, CRC-induced DNA methylation in circulating WBCs is a promising tumor marker for cancer screening studies.

\section{Acknowledgements}

The authors would like to thank Mr. Preecha Ruangvejvorachai (Department of Patholgy, Faculty of Medicine, Chulalongkorn University) for his assistance in immunohistochemistry and $\mathrm{Mr}$. Prakasit Rattanatanyong (Department of Anatomy, Faculty of Medicine, Chulalongkorn University) for his technical support.

\section{Funding}

The present study was funded by National Research Council of Thailand, The Thailand Research Fund (grant no.DPG5980005), The Anantara Siam Bangkok Hotel accompany with The Four Seasons Hotel Care for Cancer Fun Run in coordination with the Thai Red Cross Society and Chulalongkorn University.

\section{Availability of data and materials}

The datasets used during the present study are available from the corresponding author on reasonable request.

\section{Authors' contributions}

PB performed the experiments, analyzed and interpreted the data, and wrote the manuscript. PA, NKo and VA collected the specimens. CA and CP conducted the microarray and bioinformatics analyses. Nki and AM contributed to the conception and design of the study, and wrote the manuscript.

\section{Ethics approval and consent to participate}

The present study was approved by the Ethical Committee of the Faculty of Medicine, Chulalongkorn University (IRB no. 326/60). All study subjects provided written informed consent.

\section{Patient consent for publication}

Not applicable.

\section{Competing interests}

The authors declare that they have no competing interests.

\section{References}

1. Li L, Choi JY, Lee KM, Sung H, Park SK, Oze I, Pan KF, You WC Chen YX, Fang JY, et al: DNA methylation in peripheral blood: A potential biomarker for cancer molecular epidemiology. J Epidemiol 22: 384-394, 2012.
2. Kitkumthorn $\mathrm{N}$, Tuangsintanakul T, Rattanatanyong $\mathrm{P}$, Tiwawech D and Mutirangura A: LINE-1 methylation in the peripheral blood mononuclear cells of cancer patients. Clin Chim Acta 413: 869-874, 2012.

3. Puttipanyalears C, Kitkumthorn N, Buranapraditkun S, Keelawat $S$ and Mutirangura A: Breast cancer upregulating genes in stromal cells by LINE-1 hypermethylation and micrometastatic detection. Epigenomics 8: 475-486, 2016.

4. Cooper GM and Hausman RE: The development and causes of cancer. The cell: A molecular approach. 2nd edition pp 725-766, 2000.

5. Shussman N and Wexner SD: Colorectal polyps and polyposis syndromes. Gastroenterol Rep (Oxf) 2: 1-15, 2014.

6. Bujanda L, Cosme A, Gil I and Arenas-Mirave JI: Malignant colorectal polyps. World J Gastroenterol 16: 3103-3111, 2010.

7. Ferlay J, Soerjomataram I, Dikshit R, Eser S, Mathers C, Rebelo M, Parkin DM, Forman D and Bray F: Cancer incidence and mortality worldwide: Sources, methods and major patterns in GLOBOCAN 2012. Int J Cancer 136: E359-E386, 2015.

8. Levin B, Lieberman DA, McFarland B, Andrews KS, Brooks D, Bond J, Dash C, Giardiello FM, Glick S and Johnson D, et al: Screening and surveillance for the early detection of colorectal cancer and adenomatous polyps, 2008: A joint guideline from the American Cancer Society, the US Multi-Society Task Force on colorectal cancer, and the American College of Radiology. Gastroenterology 134: 1570-1595, 2008.

9. Ramsey SD, Burke W, Pinsky L, Clarke L, Newcomb P and Khoury MJ: Family history assessment to detect increased risk for colorectal cancer: Conceptual considerations and a preliminary economic analysis. Cancer Epidemiol Biomarkers Prev 14: 2494-2500, 2005.

10. Simon K: Colorectal cancer development and advances in screening. Clin Interv Aging 11: 967-76, 2016.

11. Aporntewan $\mathrm{C}$ and Mutirangura A: Connection up-and down-regulation expression analysis of microarrays (CU-DREAM): A physiogenomic discovery tool. Asian Biomed 5: 257-262, 2011.

12. Mallone R,Mannering SI,Brooks-Worrell BM,Durinovic-Belló I, Cilio CM, Wong FS and Schloot NC: Isolation and preservation of peripheral blood mononuclear cells for analysis of islet antigen-reactive $\mathrm{T}$ cell responses: Position statement of the T-Cell Workshop Committee of the Immunology of Diabetes Society. Clin Exp Immunol 163: 33-49, 2011.

13. Stathopoulos GP and Armakolas A: Differences in gene expression between individuals with multiple primary and single primary malignancies. Int J Mol Med 24: 613-622, 2009.

14. Galamb O, Sipos F, Solymosi N, Spisak S, Krenacs T, Toth K, Tulassay Z and Molnar B: Diagnostic mRNA expression patterns of inflamed, benign, and malignant colorectal biopsy specimen and their correlation with peripheral blood results. Cancer Epidemiol Biomarkers Prev 17: 2835-2845, 2008.

15. Angsuwatcharakon P, Rerknimitr R, Kongkam P, Ridtitid W, Ponauthai Y, Srisuttee R, Kitkumthorn N and Mutirangura A: Identification of pancreatic cancer in biliary obstruction patients by FRY site-specific methylation. Asian Pac J Cancer Prev 17: 4487-4490, 2016.

16. Pixberg C, Raba K, Müller F, Behrens B, Honisch E, Niederacher D, Neubauer H, Fehm T, Goering W, Schulz W, et al: Analysis of DNA methylation in single circulating tumor cells. Oncogene 36: 3223-3231, 2017.

17. Krzystek-Korpacka M, Diakowska D, Kapturkiewicz B, Bębenek M and Gamian A: Profiles of circulating inflammatory cytokines in colorectal cancer (CRC), high cancer risk conditions, and health are distinct. Possible implications for CRC screening and surveillance. Cancer Lett 337: 107-114, 2013.

18. Bhome R, Del Vecchio F, Lee GH, Bullock MD, Primrose JN, Sayan AE and Mirnezami AH: Exosomal microRNAs (exomiRs): Small molecules with a big role in cancer. Cancer Lett 420: 228-235, 2018.

19. Schwarzenbach H, Hoon DS and Pantel K: Cell-free nucleic acids as biomarkers in cancer patients. Nat Rev Cancer 11: 426-437, 2011.

20. Villarreal L, Méndez O, Salvans C, Gregori J, Baselga J and Villanueva J: Unconventional secretion is a major contributor of cancer cell line secretomes. Mol Cell Proteomics 12: 1046-1060, 2013.

21. Ball MP, Li JB, Gao Y, Lee JH, LeProust EM, Park IH, Xie B, Daley GQ and Church GM: Targeted and genome-scale strategies reveal gene-body methylation signatures in human cells. Nat Biotechnol 27: 361-368, 2009.

22. Aporntewan C, Phokaew C, Piriyapongsa J, Ngamphiw C, Ittiwut $\mathrm{C}$, Tongsima S and Mutirangura A: Hypomethylation of intragenic LINE-1 represses transcription in cancer cells through AGO2. PLoS One 6: e17934, 2011. 
23. 23. Kitkumthorn $\mathrm{N}$ and Mutirangura A: Long interspersed nuclear element-1 hypomethylation in cancer: Biology and clinical applications. Clin Epigenetics 2: 315-330, 2011.

24. Banville D, Stocco R and Shen SH: Human protein tyrosine phosphatase 1C (PTPN6) gene structure: Alternate promoter usage and exon skipping generate multiple transcripts. Genomics 27: 165-173, 1995.

25. Vinayanuwattikun C, Sriuranpong V, Tanasanvimon S, Chantranuwat $P$ and Mutirangura A: Epithelial-specific methylation marker: A potential plasma biomarker in advanced non-small cell lung cancer. J Thorac Oncol 6: 1818-1825, 2011.

26. Afik R, Zigmond E, Vugman M, Klepfish M, Shimshoni E, Pasmanik-Chor M, Shenoy A, Bassat E, Halpern Z, Geiger T, et al: Tumor macrophages are pivotal constructors of tumor collagenous matrix. J Exp Med 213: 2315-2331, 2016.

27. Xiong GF and Xu R: Function of cancer cell-derived extracellular matrix in tumor progression. J Cancer Metastasis Treat 2: 357-364, 2016

28. Said AH, Raufman JP and Xie G: The role of matrix metalloproteinases in colorectal cancer. Cancers (Basel) 6: 366-375, 2014

29. Illemann M, Bird N, Majeed A, Sehested M, Laerum OD, Lund LR, Danø K and Nielsen BS: MMP-9 is differentially expressed in primary human colorectal adenocarcinomas and their metastases. Mol Cancer Res 4: 293-302, 2006.

30. Georgescu EF, Mogoantă S, Costache A, Pârvănescu V, Totolici BD, Pătraşcu S and Stănescu C: The assessment of matrix metalloproteinase-9 expression and angiogenesis in colorectal cancer. Rom J Morphol Embryol 56: 1137-1144, 2015.

31. Herszenyi L, Hritz I, Lakatos G, Varga MZ and Tulassay Z: The behavior of matrix metalloproteinases and their inhibitors in colorectal cancer. Int J Mol Sci 13: 13240-13263, 2012.

32. Shuman Moss LA, Jensen-Taubman S and Stetler-Stevenson WG: Matrix metalloproteinases: Changing roles in tumor progression and metastasis. Am J Pathol 181: 1895-1899, 2012.

33. Luczak MW and Jagodziński PP: The role of DNA methylation in cancer development. Folia Histochem Cytobiol 44: 143-154, 2006.
34. Rasmussen SL, Krarup HB, Sunesen KG, Johansen MB, Stender MT, Pedersen IS, Madsen PH and Thorlacius-Ussing O: Hypermethylated DNA, a circulating biomarker for colorectal cancer detection. PLoS One 12: e0180809, 2017.

35. Warren JD, Xiong W, Bunker AM, Vaughn CP, Furtado LV, Roberts WL, Fang JC, Samowitz WS and Heichman KA: Septin 9 methylated DNA is a sensitive and specific blood test for colorectal cancer. BMC Med 9: 133, 2011.

36. Church TR, Wandell M, Lofton-Day C, Mongin SJ, Burger M, Payne SR, Castaños-Vélez E, Blumenstein BA, Rösch T, Osborn N, et al: Prospective evaluation of methylated SEPT9 in plasma for detection of asymptomatic colorectal cancer. Gut 63: 317-325, 2014.

37. Danese E and Montagnana M: Epigenetics of colorectal cancer: Emerging circulating diagnostic and prognostic biomarkers. Ann Transl Med 5: 279, 2017.

38. Wright M, Beaty JS and Ternent CA: Molecular Markers for Colorectal Cancer. Surg Clin North Am 97: 683-701, 2017.

39. Wang JY, Hsieh JS, Chang MY, Huang TJ, Chen FM, Cheng TL, Alexandersen K, Huang YS, Tzou WS and Lin SR: Molecular detection of APC, K-ras, and p53 mutations in the serum of colorectal cancer patients as circulating biomarkers. World J Surg 28: 721-726, 2004

40. Tutton MG, George ML, Eccles SA, Burton S, Swift RI and Abulafi AM: Use of plasma MMP-2 and MMP-9 levels as a surrogate for tumour expression in colorectal cancer patients. Int J Cancer 107: 541-50, 2003.

41. Holten-Andersen MN, Christensen IJ, Nielsen HJ Stephens RW, Jensen V, Nielsen OH, Sørensen S, Overgaard J, Lilja H, Harris A, et al: Total levels of tissue inhibitor of metalloproteinases 1 in plasma yield high diagnostic sensitivity and specificity in patients with colon cancer. Clin Cancer Res 8: $156-164,2002$.

This work is licensed under a Creative Commons Attribution-NonCommercial-NoDerivatives 4.0 International (CC BY-NC-ND 4.0) License. 